\title{
Prevalence and associated factors of COPD among Aboriginal peoples in Canada: a cross- sectional study
}

This article was published in the following Dove Press journal:

International Journal of COPD

30 June 2017

Number of times this article has been viewed

\section{Yelena Bird \\ John Moraros \\ Razi Mahmood \\ Sarvenaz Esmaeelzadeh \\ Nway Mon Kyaw Soe}

School of Public Health, University of Saskatchewan, Saskatoon, SK, Canada

Correspondence: Yelena Bird School of Public Health, University of Saskatchewan, 104 Clinic Place, E-Wing, Health Sciences, Room 3322, Saskatoon, SK S7N 2Z4, Canada

Tel +l 3069668432

Fax + I 3069667920

Email yelena.bird@usask.ca
Background: COPD among Aboriginal peoples in Canada is a major public health concern. This study was conducted in order to determine the prevalence and association between certain risk factors and COPD among the 35-year-old or older Aboriginal peoples in Canada.

Methods: This is a cross-sectional study. It uses data from Statistics Canada's Aboriginal Peoples Survey (APS), 2012. It consists of 8,117 self-identified Aboriginal peoples, aged 35 years old or older from all Canadian provinces and territories. The study outcomes centered on evaluating the prevalence and associated factors of COPD.

Results: This study found that $6.80 \%$ of the participants self-reported having COPD. Results of the logistic regression analysis show that COPD was significantly higher among daily smokers (odds ratio [OR], 2.28; 95\% confidence interval [95\% CI], 1.65-3.14), aged 55 years or older (OR, 3.04; 95\% CI, 2.14-4.30), who earned \$5,000-\$9,999 per annum (OR, 4.21; 95\% CI, 2.39-7.41) and needed health care over the past 12 months and did not receive it (OR, 1.83; 95\% CI, 1.27-2.65).

Conclusion: The findings of our study show that COPD is strongly associated with Aboriginal peoples, who are older, smoke, have a low socioeconomic status (SES) and do not have access to health care when needed. Clinicians, health care professionals, medical/public health organizations, researchers and patients will greatly benefit from additional research in this common, serious and often overlooked disease among Aboriginal peoples in Canada.

Keywords: COPD, smoking, socioeconomic status, Aboriginal peoples, Canada

\section{Introduction}

COPD is a major public health problem. The World Health Organization (WHO) estimated COPD to be the fourth leading cause of death worldwide in 2013 and projects it to become the third most common cause of death by $2030 .^{1,2}$ In Canada, it is estimated that COPD afflicts $\sim 4 \%$ of the general population aged 35 years or older, and the rates are even higher at $6.5 \%$ for its Aboriginal population. ${ }^{3}$ COPD places a significant strain on the Canadian health care system with an estimated cost of $\$ 1.23$ billion CAD in 2008 alone. ${ }^{4,5}$

The prevalence of COPD is likely underestimated, as the statistics reported are not confirmed by objective lung function tests. ${ }^{3}$ Chronic lower respiratory disease (the majority consisting of COPD) is the fourth leading cause of death in Canada. ${ }^{6}$ Furthermore, COPD is the most common cause of chronic disease hospitalization in Canada. ${ }^{7}$ Studies suggest that the Aboriginal population of Canada has a higher incidence of COPD and a greater burden of disease compared to the non-Aboriginal Canadian population. ${ }^{8,9}$ These differences are likely due to disparities in smoking, demographic, 
socioeconomic and environmental risk factors between the Aboriginal and non-Aboriginal population of Canada.

The prevalence of smoking among Aboriginal peoples (39\%) was nearly two times higher than non-Aboriginal Canadians (20.5\%) according to the Canadian Community Health Survey. ${ }^{10}$ Among Aboriginal peoples, the highest prevalence of smoking was seen among the Inuit peoples (49\%), followed by First Nations (40.1\%) and Métis (36.8\%). ${ }^{10}$ This is an important finding as smoking has been identified as the dominant cause for COPD in both men and women, ${ }^{11}$ suggesting that there is an increased burden of COPD in the Aboriginal peoples of Canada.

Socioeconomic status (SES) is associated with many diseases. Annual personal income and education are frequently used as proxies for SES. Multiple studies have established the association between low income and level of education with COPD. ${ }^{12-15}$ Studies have shown a consistent gap in the median income between the Aboriginal and non-Aboriginal Canadian population. ${ }^{16}$ With respect to education, approximately half (48.4\%) of the Aboriginal population identified as having completed post-secondary education, when compared to $64.7 \%$ of the non-Aboriginal Canadian population. ${ }^{17}$ Apart from smoking and SES, there are also other factors associated with COPD including demographic (sex, age, marital status and body mass index [BMI] $)^{12-14}$ and environmental variables (overcrowding, having a regular medical doctor, access to health care when needed). ${ }^{1,12,13}$ The purpose of this study is to determine the prevalence and association between certain risk factors and COPD among the 35-year-old or older Aboriginal peoples in Canada.

\section{Methods}

\section{Study design}

Our study used data from Statistics Canada's Aboriginal Peoples Survey (APS) in 2012. This is a cross-sectional survey. The population of interest is the Aboriginal peoples of Canada (First Nations, Métis and Inuit) living in private dwellings. Individuals living on Indian reserves and certain settlements in the Yukon and Northwest Territories were not included. Respondents were chosen based on self-identification as being Aboriginal or having Aboriginal ancestry on the 2011 National Health Survey (NHS). The survey design and weighting allow for population-based estimates. ${ }^{18}$

\section{Participants}

The 2012 APS consists of 24,803 Aboriginal respondents from all Canadian provinces and territories. To maintain consistency in the reporting of our findings with the general
Canadian statistics on COPD (which only considers individuals aged 35 years old or older), ${ }^{19}$ our study focused on 8,117 participants.

\section{Variables \\ Outcome variable}

The outcome variable used in this study was self-reported COPD status. The question asked whether the respondent has chronic bronchitis, emphysema or COPD. The outcome variable was coded as "yes" or "no". Respondents who were unsure if they had COPD or refused to answer the question were removed from the study.

\section{Independent variables}

The independent variables of interest for this study included smoking status, demographic characteristics (Aboriginal identity, sex, age group, marital status and BMI), SES indicators (income and education) and environmental variables (crowding index, having a regular medical doctor and access to health care over the past 12 months when needed).

Smoking status was self-reported as being daily, occasional or not at all. Demographic characteristics of the respondent included Aboriginal identity (First Nations, Métis, Inuit), sex (male/female), age (35-44 years old, 45-54 years old and 55 years or older), marital status (married or living common-law, separated or divorced or widowed and single never married) and BMI (underweight, normal weight, overweight and obese). Socioeconomic indicators included total personal income in 2011 ( $<\$ 5,000$ or none, $\$ 5,000-\$ 9,999$, \$10,000-\$19,999, \$20,000-\$29,999, \$30,000-\$39,999, $\$ 40,000-\$ 49,999$ and $\$ 50,000$ and greater) and level of education (post-secondary certification or university degree, completed secondary education and/or some post-secondary education and did not complete secondary education). Environmental variables included a crowding index (one person or fewer per room and more than one person per room), having a regular medical doctor (yes or no) and whether the respondent needed health care over the past 12 months and did not receive it (yes or no).

\section{Data analysis}

Survey weights provided in the public use microdata file (PUMF) were used for data analysis to allow generalization of our findings to the population of interest (Aboriginal peoples, 35 years or older, living off reserve). Descriptive statistics were assessed to determine the frequencies of the various independent variables (smoking status, demographic characteristics, socioeconomic indicators and environmental variables). 
Certain variables were recoded (age group, BMI, marital status and education) based on our literature review and findings from descriptive statistics. Descriptive statistics of our independent variables were compared to COPD status.

Univariate analysis was conducted to assess the crude association between each of the independent variables (smoking status, demographic characteristics, SES indicators and environmental variables) and the outcome variable of interest (self-reported COPD). The level of significance $\alpha=0.25$ was used during univariate analysis (ie, $P$-value $>0.25$ was not statistically significant). Multicollinearity was assessed for all the independent variables found to be statistically significant from the univariate analysis. Using the PROC SURVEYLOGISTIC command, logistic regression modeling was carried out to determine the association between the independent variables and COPD.

The assumptions of logistic regression were checked, and manual backwards selection strategy was used when constructing our model. As variables were removed from the model, confounding was assessed at each stage. A change of $20 \%$ or more in the regression coefficient of the primary predictor ( $\Delta \beta \geq 20 \%$ ) suggested that the variable is a confounder. If a variable was found to be a confounder, it would remain in the model. All possible two-way interactions involving the primary predictor were assessed using a $P$-value of 0.05 . The HosmerLemeshow goodness-of-fit test was used to assess model fitness. Data analysis was conducted using SAS version 9.4.

\section{Results \\ Descriptive statistics}

Our analysis found that of the 8,117 Aboriginal peoples, aged 35 years old or older, $6.80 \%$ of them self-reported having COPD. Daily smokers had the highest prevalence of COPD (9.44\%) when compared to occasional smokers $(6.22 \%)$ and those who did not smoke at all (5.40\%).

When examining the demographic characteristics of our study population, Aboriginals who were identified as Métis had the highest prevalence of self-reported COPD (7.93\%) when compared to First Nations (6.61\%) and Inuit (3.21\%). Females $(7.75 \%)$ had higher prevalence of COPD when compared to males $(5.67 \%)$. COPD by age group increased as age increased, with individuals aged 55 years or older $(11.05 \%)$ having the highest prevalence. Separated divorced or widowed respondents had the highest prevalence of COPD (11.38\%) when compared to single or never married (7.94\%) and married or living in a common-law relationship (5.25\%). When examining the BMI, individuals classified as underweight had the highest prevalence of COPD (13.21\%), followed by those classified as obese $(8.38 \%)$, normal weight (7.60\%) and overweight (4.70\%).

When considering the socioeconomic indicators (income and education), an inverse relationship was observed, whereby as education or income increased, COPD prevalence decreased. Individuals who earned $\$ 50,000$ or greater reported the lowest prevalence of COPD (2.66\%), while individuals who earned \$5,000-\$9,999 reported the highest (14.61\%). Respondents who completed either a certificate program or a university degree had the lowest prevalence of COPD (4.52\%), while individuals who did not complete secondary education had the highest $(9.66 \%)$.

The relationship between environmental variables and COPD prevalence was as follows: crowded accommodations (5.23\%) vs uncrowded accommodations (6.93\%), having a regular medical doctor, yes $(7.58 \%)$ vs no $(4.30 \%)$, and not having access to health care over the past 12 months when needed, yes $(12.10 \%)$ vs no $(5.95 \%)$ (Table 1$)$.

\section{Univariate analysis}

Univariate analysis was conducted with a level of significance of $\alpha=0.25$. Statistically significant associations found at this stage include type of smoker $(P$-value $<0.0001)$, Aboriginal identity $(P$-value $=0.0023)$, sex $(P$-value $=0.0930)$, age group $(P$-value $<0.0001)$, marital status $(P$-value $<0.0001)$, BMI $(P$-value $=0.0268)$, income $(P$-value $<0.0001)$, education $(P$-value $<0.0001)$, having a regular medical doctor $(P$-value $=0.1174)$ and receiving health care over the past 12 months when needed $(P$-value $<0.0001)$. Odds ratios (ORs) for univariate analysis with respect to the reference category listed are presented in Table 2.

\section{Logistic regression model}

Variables identified as significant in the univariate analysis were initially tested for multicollinearity. Tolerance values ranged from 0.81 to 0.96 , indicating that there is no evidence of multicollinearity. The Hosmer-Lemeshow test was used as the final model diagnostic, and it indicated goodness of fit $(P$-value $=0.3480)$.

Multivariate logistic regression analysis examined the association between self-reported COPD and the independent variables. Results of this analysis found that daily smokers were 2.28 times more likely to have COPD (OR, 2.28; 95\% confidence interval $[95 \% \mathrm{CI}], 1.65-3.14)$ when compared to individuals who do not smoke. Inuit were 58\% less likely to report having COPD (OR, 0.42; 95\% CI, 0.24-0.74) when compared to First Nations. When examining the association between age group and COPD, individuals aged $45-54$ years old 
Table I Descriptive statistics of Aboriginal cohort aged 35 years or older

\begin{tabular}{|c|c|c|c|c|}
\hline \multicolumn{2}{|l|}{ Outcome variables } & \multicolumn{2}{|l|}{ Percentage } & \multirow{2}{*}{$\begin{array}{l}\text { Total } \\
552\end{array}$} \\
\hline \multirow[t]{2}{*}{$\operatorname{COPD}(n=8,117)$} & With COPD & 6.80 & & \\
\hline & Without COPD & 93.20 & & 7,565 \\
\hline \multicolumn{2}{|l|}{ Independent variables } & With COPD & Without COPD & Tota \\
\hline Type of smoker & Daily & 9.44 & 90.56 & 2,659 \\
\hline \multirow[t]{2}{*}{$(n=8,080)$} & Occasional & 6.22 & 93.78 & 643 \\
\hline & Not at all & 5.40 & 94.60 & 4,778 \\
\hline \multicolumn{5}{|c|}{ Demographic characteristics } \\
\hline Aboriginal identity & First Nations & 6.61 & 93.39 & 3,508 \\
\hline \multirow[t]{2}{*}{$(\mathrm{n}=8,058)$} & Métis & 7.93 & 92.07 & 3,583 \\
\hline & Inuit & 3.21 & 96.79 & 967 \\
\hline \multirow[t]{2}{*}{$\operatorname{Sex}(n=8,117)$} & Male & 5.67 & 94.33 & 3,705 \\
\hline & Female & 7.75 & 92.25 & 4,412 \\
\hline \multirow[t]{3}{*}{ Age group $(n=8,117)$} & $35-44$ years & 3.69 & 96.31 & 3,636 \\
\hline & $45-54$ years & 7.08 & 92.92 & $\mathrm{I}, 948$ \\
\hline & $55+$ years & 11.05 & 88.95 & 2,533 \\
\hline Marital status & Single or never married & 7.94 & 92.06 & $\mathrm{I}, 448$ \\
\hline \multirow[t]{2}{*}{$(n=8,114)$} & Separated, divorced or widowed & 11.38 & 88.62 & $\mathrm{I}, 406$ \\
\hline & Married or living common-law & 5.25 & 94.75 & 5,260 \\
\hline \multirow[t]{4}{*}{ BMI $(n=7,746)$} & Obese & 8.38 & 91.62 & 2,519 \\
\hline & Overweight & 4.70 & 95.30 & 2,806 \\
\hline & Normal weight & 7.60 & 92.40 & 2,315 \\
\hline & Underweight & $|3.2|$ & 86.79 & 106 \\
\hline \multicolumn{5}{|c|}{ Socioeconomic indicators } \\
\hline Total personal & $\$ 50,000$ and greater & 2.66 & 97.34 & 2,406 \\
\hline income in 2011 & $\$ 40,000-\$ 49,999$ & 3.91 & 96.09 & 717 \\
\hline \multirow[t]{5}{*}{$(n=7,569)$} & $\$ 30,000-\$ 39,999$ & 5.80 & 94.20 & 931 \\
\hline & $\$ 20,000-\$ 29,999$ & 6.42 & 93.58 & 950 \\
\hline & $\$ 10,000-\$ 19,999$ & 13.83 & 86.17 & $\mathrm{I}, 374$ \\
\hline & $\$ 5,000-\$ 9,999$ & $|4.6|$ & 85.39 & 486 \\
\hline & $<\$ 5,000$ & 7.09 & 92.91 & 705 \\
\hline $\begin{array}{l}\text { Highest level of } \\
\text { education attained }\end{array}$ & $\begin{array}{l}\text { Post-secondary certification or } \\
\text { university degree }\end{array}$ & 4.52 & 95.48 & 3,497 \\
\hline \multirow[t]{3}{*}{$(n=8,016)$} & Completed secondary education and/ & 6.94 & 93.06 & 1,932 \\
\hline & or some post-secondary education & & & \\
\hline & Did not complete secondary education & 9.66 & 90.34 & 2,587 \\
\hline \multicolumn{5}{|l|}{ Environmental variables } \\
\hline Crowding index & Greater than one person per room & 5.23 & 94.77 & 555 \\
\hline$(n=8,027)$ & One person or fewer per room & 6.93 & 93.07 & 7,472 \\
\hline Regular medical & Yes & 7.58 & 92.42 & 6,184 \\
\hline doctor $(n=8,1 \mid 2)$ & No & 4.30 & 95.70 & 1,928 \\
\hline Health care needed & Yes & 12.10 & 87.90 & 1,116 \\
\hline but not received past & No & 5.95 & 94.05 & 6,970 \\
\hline 12 months $(n=8,086)$ & & & & \\
\hline
\end{tabular}

Abbreviation: BMI, body mass index.

(OR, 2.56; 95\% CI, 1.73-3.78) and individuals aged 55 years or older (OR, 3.04; 95\% CI, 2.14-4.30) were more likely to have COPD when compared to individuals aged $35-44$ years. Income had the following results when compared to the association of COPD to individuals who earned $\$ 50,000$ per year and greater: individuals earning $\$ 30,000-\$ 39,999$ per year (OR, 1.93; 95\% CI, 1.04-3.58), \$10,000-\$19,999 (OR, 3.31; 95\% CI, 1.99-5.52), \$5,000-\$9,999 (OR, 4.21; 95\% $\mathrm{CI}, 2.39-7.41)$ and $<\$ 5,000$ per year (OR, 1.88; 95\% CI, 1.04-3.40). Individuals who needed health care over the past 12 months and did not receive it were more likely (OR, 1.83; 95\% CI, 1.27-2.65) to have COPD compared to individuals who received health care or did not need it over the past 12 months (Table 3). Sex, BMI, level of education, the crowding index and having a regular medical doctor were not found to be statistically significant.

\section{Discussion}

This study was conducted in order to determine the prevalence and association between certain risk factors and 
Table 2 Univariate analysis of self-reported COPD among Aboriginal cohort aged 35 years or older

\begin{tabular}{|c|c|c|c|}
\hline \multicolumn{2}{|l|}{ Variables } & \multirow{2}{*}{$\begin{array}{l}\text { Odds ratio (95\% } \\
\text { CI: lower to upper) } \\
2.55(1.92-3.39) \\
\end{array}$} & \multirow{2}{*}{$\begin{array}{c}\begin{array}{l}\text { P-value } \\
(\alpha=0.25)\end{array} \\
<0.000 I\end{array}$} \\
\hline Type of smoker (ref=not at all) & Daily & & \\
\hline & Occasional & $1.65(0.96-2.85)$ & \\
\hline \multicolumn{4}{|l|}{ Demographic characteristics } \\
\hline Aboriginal identity (ref=First & Métis & I.0I (0.76-I.34) & 0.0023 \\
\hline Nations) & Inuit & $0.43(0.26-0.7 I)$ & \\
\hline Sex (ref=female) & Female & $0.78(0.58-1.04)$ & 0.0930 \\
\hline Age group (ref=ages $35-44$ years & $45-54$ years & $2.63(1.81-3.80)$ & $<0.0001$ \\
\hline old) & $55+$ years & $3.01(2.19-4.13)$ & \\
\hline 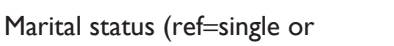 & Separated, divorced or widowed & $1.57(1.09-2.26)$ & $<0.000$ I \\
\hline never married) & Married or living common-law & $0.70(0.49-0.99)$ & \\
\hline \multirow[t]{3}{*}{ BMI (ref=normal weight) } & Obese & $0.95(0.69-1.31)$ & 0.0268 \\
\hline & Overweight & $0.65(0.44-0.95)$ & \\
\hline & Underweight & $2.14(0.84-5.49)$ & \\
\hline \multicolumn{4}{|l|}{ Socioeconomic indicators } \\
\hline Total personal income & $\$ 40,000-\$ 49,999$ & $1.24(0.66-2.3 \mathrm{I})$ & $<0.0001$ \\
\hline \multirow[t]{5}{*}{$(\mathrm{ref}=\$ 50,000$ and greater $)$} & $\$ 30,000-\$ 39,999$ & $2.02(1.13-3.63)$ & \\
\hline & $\$ 20,000-\$ 29,999$ & $2.07(1.18-3.63)$ & \\
\hline & $\$ 10,000-\$ 19,999$ & $4.80(3.02-7.61)$ & \\
\hline & $\$ 5,000-\$ 9,999$ & $5.24(3.08-8.93)$ & \\
\hline & $<\$ 5,000$ & $2.27(1.30-3.97)$ & \\
\hline Highest level of education & Completed secondary education & $1.21(0.84-1.73)$ & $<0.000$ I \\
\hline attained (ref=post-secondary & and/or some post-secondary education & & \\
\hline certification or university degree) & Did not complete secondary education & $2.25(1.62-3.14)$ & \\
\hline \multicolumn{4}{|l|}{ Environmental variables } \\
\hline $\begin{array}{l}\text { Crowding index (ref=one person } \\
\text { or fewer per room) }\end{array}$ & Greater than one person per room & $0.96(0.54-1.70)$ & 0.8773 \\
\hline Regular medical doctor (ref=yes) & No & $1.33(0.93-1.91)$ & 0.1174 \\
\hline $\begin{array}{l}\text { Health care needed but not } \\
\text { received past } 12 \text { months (ref=no) }\end{array}$ & Yes & $2.71(1.94-3.78)$ & $<0.000$ I \\
\hline
\end{tabular}

Abbreviation: $\mathrm{BMI}$, body mass index.

Table 3 The association between risk factors and COPD via logistic regression modeling

\begin{tabular}{|c|c|c|c|}
\hline \multicolumn{2}{|l|}{ Variables } & \multirow{2}{*}{$\begin{array}{l}\text { Odds ratio (95\% } \\
\text { CI: lower to upper) } \\
2.28(1.65-3.14)\end{array}$} & \multirow{2}{*}{$\begin{array}{l}\begin{array}{l}P \text {-value } \\
(\alpha=0.05)\end{array} \\
<0.0001\end{array}$} \\
\hline Type of smoker (ref=not at all) & Daily & & \\
\hline & Occasional & $1.64(0.873-3.14)$ & \\
\hline \multicolumn{4}{|l|}{ Demographic characteristics } \\
\hline Aboriginal identity (ref=First & Métis & $0.90(0.66-1.23)$ & 0.0113 \\
\hline Nations) & Inuit & $0.42(0.24-0.74)$ & \\
\hline \multirow[t]{2}{*}{ Age group (ref=ages $35-44$ years) } & $45-54$ years & $2.56(1.73-3.78)$ & $<0.0001$ \\
\hline & $55+$ years & $3.04(2.14-4.30)$ & \\
\hline Marital status (ref $=$ single or never & Separated, divorced or widowed & $\mathrm{I} .33(0.87-2.04)$ & 0.0131 \\
\hline married) & Married or living common-law & $0.77(0.50-1.18)$ & \\
\hline \multicolumn{4}{|l|}{ Socioeconomic indicators } \\
\hline Total personal income & $\$ 40,000-\$ 49,999$ & $1.07(0.56-2.03)$ & $<0.0001$ \\
\hline \multirow[t]{5}{*}{ (ref $=\$ 50,000$ and greater) } & $\$ 30,000-\$ 39,999$ & $1.93(1.04-3.58)$ & \\
\hline & $\$ 20,000-\$ 29,999$ & $\mathrm{I} .57(0.87-2.88)$ & \\
\hline & $\$ 10,000-\$ 19,999$ & $3.31(1.99-5.52)$ & \\
\hline & $\$ 5,000-\$ 9,999$ & $4.21(2.39-7.41)$ & \\
\hline & $<\$ 5,000$ & I.88 (I.04-3.40) & \\
\hline \multicolumn{4}{|l|}{ Environmental variables } \\
\hline $\begin{array}{l}\text { Health care needed but not } \\
\text { received past } 12 \text { months ( } r e f=\text { no) }\end{array}$ & Yes & $\mathrm{I} .83(\mathrm{I} .27-2.65)$ & 0.0012 \\
\hline
\end{tabular}


COPD among the 35-year-old or older Aboriginal peoples in Canada. As the Aboriginal population is one of the fastest growing and most vulnerable sub-segments of the Canadian population, ${ }^{20}$ the findings of this study provide meaningful insight and knowledge into the issue of COPD. It specifically takes into account the smoking, demographic, socioeconomic and environmental characteristics and the role they play in potentially increasing the burden of COPD among the Aboriginal population of Canada.

Smoking is known to be a direct cause for COPD. ${ }^{11}$ The 2012 APS data set used the following question to ascertain smoking status: "At the present time, do you smoke cigarettes daily, occasionally or not at all?" Interestingly, the participants reporting "not at all" had a higher prevalence of COPD $(5.40 \%)$ compared to the general Canadian population. This may be due to the fact that former smokers probably responded "not at all" to their present smoking status but are known to be at an increased risk for COPD compared to never smokers. ${ }^{21}$ A second possible explanation may be that former smokers have an increased exposure to environmental tobacco smoke, another predictor for COPD. ${ }^{22}$

Our study found the prevalence of smoking among the 35 -year-old or older Aboriginal population to be $\sim 40 \%$ (32.91\% daily smokers and 7.96\% occasional smokers) (Table 1). This is in stark contrast to the prevalence of smoking reported among the same age group within the general Canadian population (18.62\%). ${ }^{23,24}$ Correspondingly, selfreported cases of COPD place a larger burden of disease on the Aboriginal population (6.8\%) when compared to the general Canadian population $(4 \%){ }^{3,25}$ Further compounding this issue is the fact that the prevalence of COPD in Canada has been underestimated by a magnitude of two- to sixfold when comparing self-reported COPD cases to those with an actual medical diagnosis. ${ }^{3}$ It is fair to assume that similar, if not greater, underreporting trends may be taking place among the Aboriginal population in Canada and, thus, warrant immediate attention, community engagement and further study.

The prevalence of most chronic diseases increases with age, and COPD is of no difference. From our results, individuals aged 55 years or older are approximately three times more likely to report COPD when compared to individuals aged 35-44 years. This is in line with the results reported in previous studies. ${ }^{13,26}$ SES is known to be a key social determinant of health. Our study found that Aboriginal peoples earning lower annual personal incomes $(<\$ 20,000)$ were more likely to have COPD when compared to Aboriginal peoples earning personal incomes of $\$ 50,000$ or greater, thus making low SES an independent risk factor for COPD. This finding is supported by other research studies, which report that Aboriginal peoples making less than the median income $(<\$ 20,060)$ are at greater risk to develop COPD. ${ }^{27-29}$

When investigating the association between Aboriginal identity and self-reported COPD, there was no statistically significant difference between First Nations and Métis. However, the Inuit population was less likely to report having COPD when compared to First Nations (OR, 0.42; 95\% CI, 0.24-0.74). This finding is counterintuitive, as previous studies including our own show the Inuit population to have the highest prevalence of smoking ${ }^{10,30}$ among Aboriginal peoples (55.29\% of Inuit were daily smokers when compared to $30.27 \%$ of First Nations and $29.68 \%$ of Métis). One possible explanation may lie in their lack of access to a regular medical doctor. Our study found that a larger proportion of First Nations $(80.59 \%)$ and Métis $(82.51 \%)$ peoples, aged 35 years or older, had a regular medical doctor when compared to Inuit (36.47\%). This finding suggests that the Inuit group may be unaware and/or undiagnosed for COPD.

Poor access to health care is an unfortunate but all too common theme when discussing Aboriginal peoples' health-related issues. ${ }^{31}$ Our study found that individuals with self-reported COPD were unable to access health care when needed over the past 12 months. This can lead to increased morbidity and mortality as well as exacerbation of symptoms, which are commonly seen in COPD patients from marginalized groups. ${ }^{9}$ These cases can oftentimes be treated or even prevented with appropriate interventions. Current strategies for prevention, diagnosis and treatment of COPD require regular access to health care providers to ensure receipt of proper medications, regular assessment of the disease, teaching self-management techniques and tobacco cessation/ education programs. ${ }^{32}$

\section{Recommendations}

Smoking is known to be the dominant cause for COPD. ${ }^{11}$ Along with initiatives centered on the treatment of tobacco dependence, comprehensive public health policy, promotion and education programs specifically tailored for the Aboriginal population of Canada can prove particularly effective in addressing COPD. Clinical treatments need to integrate both behavioral and/or pharmacological interventions. Physicians and health care providers may require increased awareness and training with tools such as spirometers $^{33}$ to better detect and treat COPD. Policies, promotion initiatives and education programs can help create supportive environments that encourage Aboriginal peoples in their 
attempts to quit smoking and stay tobacco free. Measures that curb the tobacco supply side such as taxation, price control, stopping contraband cigarettes, advertising restrictions, dissemination of culturally appropriate information, community engagement and establishment of smoke-free legislation are important to reduce smoking rates and exposure to secondhand smoke and prevent individuals from developing COPD.

\section{Conclusion}

This study suggests that COPD among Aboriginal peoples in Canada is a major public health concern. The findings of our study show that COPD is strongly associated with Aboriginal peoples, who are older, smoke, have a low SES and do not have access to health care when needed. COPD interventions specifically tailored for this particularly vulnerable group are very much needed. Clinicians, health care professionals, medical/public health organizations, researchers and patients will greatly benefit from additional research in this common, serious and often overlooked disease among Aboriginal peoples in Canada.

\section{Acknowledgments}

The APS is a national survey of First Nations people living off reserve, Métis and Inuit living in Canada. It is a product of Statistics Canada. The views and results presented herein are those of the authors/authorized users and not those of Statistics Canada. We gratefully acknowledge Statistics Canada for kindly granting us access to the microdata files. This research was supported in part by a matching collaborative grant from the Lung Association of Saskatchewan and the School of Public Health, University of Saskatchewan. The APS was implemented with the cooperation, support and funding of Statistics Canada. The publishing of analysis and results from research using any of the data products in research communications such as scholarly papers and journals is permitted by Statistics Canada and exempt from ethics approval because it relies on the use of Statistics Canada public files and secondary analysis of anonymous data (Tri-Council Policy Statement, articles 2.2 and 2.4, respectively). Participation in this survey was voluntary.

\section{Author contributions}

YB, JM, RM, SE and NMKS contributed to the concept and design of this study and undertook data analysis and interpretation. All authors contributed toward drafting and critically revising the paper and agree to be accountable for all aspects of the work.

\section{Disclosure}

The authors report no conflicts of interest in this work.

\section{References}

1. Gershon AS, Khan S, Klein-Geltink J, et al. Asthma and chronic obstructive pulmonary disease (COPD) prevalence and health services use in Ontario, Metis: a population-based cohort. PLoS One. 2014; 9(4):e95899.

2. WHO [webpage on the Internet]. Burden of COPD. WHO; 2011. Available from: http://www.who.int/respiratory/copd/burden/en/. Accessed April 28, 2017.

3. Evans J, Chen Y, Camp PG, Bowie DM, McRae L. Estimating the prevalence of COPD in Canada: reported diagnosis versus measured airflow obstruction. Health Rep. 2014;25(3):3-11.

4. Government of Canada [webpage on the Internet]. Economic Burden of Illness in Canada Custom Report. 2017. Available from: http://ebicfemc.phac-aspc.gc.ca/custom-personnalise/results-national-resultats. php. Accessed April 28, 2017.

5. Diener A, Dugas JM, Eng K, et al. Economic Burden of Illness in Canada, 2005-2008. 2014. Available from: http://www.phac-aspc. gc.ca/publicat/ebic-femc/2005-2008/assets/pdf/ebic-femc-2005-2008eng.pdf. Accessed June 12, 2017.

6. Ejiofor S, Stolk J, Fernandez P, Stockley R. Patterns and characterization of COPD exacerbations using real-time data collection. Int JChron Obstruct Pulmon Dis. 2017;12:427-434.

7. Camp PG, Phd P, Hernandez P, et al. Pulmonary rehabilitation in Canada: a report from the Canadian Thoracic Society COPD clinical assembly. Can Respir J. 2015;22(3):147-152.

8. Ospina MB, Rowe BH, Voaklander D, Senthilselvan A, Stickland MK, King M. Emergency department visits after diagnosed chronic obstructive pulmonary disease in aboriginal people in Alberta, Canada. CJEM. 2016;18(6):420-428.

9. Reading J. The Crisis of Chronic Disease among Aboriginal Peoples: A Challenge for Public Health, Population Health and Social Policy. 2017. Available from: http://cahr.uvic.ca/nearbc/documents/2009/ CAHR-B2-Chronic-Disease.pdf. Accessed April 28, 2017.

10. Smoke-Free. Smoking among Aboriginal Canadians. 2017. Available from: http://www.smoke-free.ca/factsheets/pdf/cchs/aboriginal.pdf. Accessed April 28, 2017.

11. U.S. Department of Health and Human Services. The Health Consequences of Smoking: 50 Years of Progress. A Report of the Surgeon General. Atlanta, GA: U.S. Department of Health and Human Services, Centers for Disease Control and Prevention, National Center for Chronic Disease Prevention and Health Promotion, Office on Smoking and Health; 2014.

12. Hossain A, Konrad S, Dosman JA, Senthilselvan A, McCrosky J, Pahwa $\mathrm{P}$. The determinants of chronic bronchitis in Aboriginal children and youth. Can Respir J. 2012;19(6):e75-e80.

13. Konrad S, Hossain A, Senthilselvan A, et al. Chronic bronchitis in Aboriginal people-prevalence and associated factors. Chronic Dis Inj Can. 2013;33(4):218-225.

14. Walker SL, Saltman DL, Colucci R, Martin L; Canadian Lung Association Advisory Committee. Awareness of risk factors among persons at risk for lung cancer, chronic obstructive pulmonary disease and sleep apnea: a Canadian population-based study. Can Respir J. 2010;17(6):287-294.

15. Senthilselvan A, Lawson J, Rennie DC, Dosman JA. Stabilization of an increasing trend in physician-diagnosed asthma prevalence in Saskatchewan, 1991 to 1998. Chest. 2003;124(2):438-448.

16. Wilson D, Macdonald D. The Income Gap between Aboriginal Peoples and the Rest of Canada. Ottawa, ON: Canadian Centre for Policy Alternatives; 2010.

17. Ferguson SJ, Zhao J. The Educational Attainment of Aboriginal Peoples in Canada NHS in Brief. 2017. Available from: http://www12.statcan. gc.ca/nhs-enm/2011/as-sa/99-012-x/99-012-x2011003_3-eng.pdf. Accessed March 3, 2017. 
18. Cloutier E, Langlet É. Aboriginal Peoples Survey, 2012: Concepts and Methods Guide Concepts and Methods. 2014. Available from: http:// www.statcan.gc.ca/pub/89-653-x/89-653-x2013002-eng.pdf. Accessed April 28, 2017.

19. Morrison H, Odrowaz-Pieniazek J, Olivier A, et al. Chronic Diseases and Injuries in Canada a Publication of the Public Health Agency of Canada CDIC Editorial Board Centers for Disease Control and Prevention Monitoring Chronic Diseases in Canada: The Chronic Disease Indicator Framework. 2017. Available from: http://www.phac-aspc. gc.ca/publicat/hpcdp-pspmc/34-1-supp/assets/pdf/34-S1_E_v6.pdf. Accessed April 28, 2017.

20. Turner A, Crompton S, Langlois S. Aboriginal Peoples in Canada: First Nations People, Métis and Inuit. 2011. Available from: http://www12. statcan.gc.ca/nhs-enm/2011/as-sa/99-011-x/99-011-x2011001-eng.pdf. Accessed March 3, 2017.

21. Terzikhan N, Verhamme KMC, Hofman A, Stricker BH, Brusselle GG, Lahousse L. Prevalence and incidence of COPD in smokers and non-smokers: the Rotterdam study. Eur J Epidemiol. 2016;31(8): 785-792.

22. Hagstad S, Bjerg A, Ekerljung L, et al. Passive smoking exposure is associated with increased risk of COPD in never smokers. Chest. 2014;145(6):1298-1304.

23. CANSIM [webpage on the Internet]. 051-0001 - Estimates of Population, by Age Group and Sex for July 1, Canada, Provinces and Territories. 2017. Available from: http://www5.statcan.gc.ca/cansim/ a26?id=510001. Accessed April 28, 2017.

24. Statistics Canada [webpage on the Internet]. Smokers, by Age Group and Sex (Number of Persons). 2017. Available from: http://www.statcan. gc.ca/tables-tableaux/sum-som/101/cst01/health73a-eng.htm. Accessed April 28, 2017.

25. Betancourt MT, Roberts KC, Bennett T-L, Driscoll ER, Jayaraman G, Pelletier L. Monitoring chronic diseases in Canada: the chronic disease indicator framework. Chronic Dis Inj Can. 2014;34(suppl 1):1-30.
26. Afonso AS, Verhamme KM, Sturkenboom MC, Brusselle GG. COPD in the general population: prevalence, incidence and survival. Respir Med. 2011;105(12):1872-1884.

27. Gionet L, Roshanafshar S [webpage on the Internet]. Select Health Indicators of First Nations People Living Off Reserve, Métis and Inuit. 2017. Available from: http://www.statcan.gc.ca/pub/82-624-x/2013001/ article/11763-eng.htm. Accessed April 28, 2017.

28. Kanervisto M, Vasankari T, Laitinen T, Heliövaara M, Jousilahti P, Saarelainen S. Low socioeconomic status is associated with chronic obstructive airway diseases. Respir Med. 2011;105(8):1140-1146.

29. Eisner MD, Blanc PD, Omachi TA, et al. Socioeconomic status, race and COPD health outcomes. J Epidemiol Community Health. 2011; 65(1):26-34.

30. Public Health Agency of Canada. Fast facts about Chronic Obstructive Pulmonary Disease (COPD). Chronic Dis Can. 2011;200:1-5.

31. Wien F, Loppie C, Wien RF. Charlotte Loppie Reading Ph Health Inequalities and Social Determinants of Aboriginal Peoples' Health Health Inequalities and Social Determinants of Aboriginal Peoples' Health. 2017. Available from: http://www.nccah-ccnsa.ca/docs/ social determinates/NCCAH-loppie-Wien_report.pdf. Accessed April 28, 2017.

32. Vogelmeier CF, Criner GJ, Martinez FJ, et al. Global strategy for the diagnosis, management, and prevention of chronic obstructive lung disease 2017 report: GOLD executive summary. Arch Bronconeumol. 2017;53(3):128-149.

33. Coates A, Graham B, Mcfadden R, et al. Spirometry in primary care. Can Respir J. 2013;20(1):13-21.
International Journal of COPD

\section{Publish your work in this journal}

The International Journal of COPD is an international, peer-reviewed journal of therapeutics and pharmacology focusing on concise rapid reporting of clinical studies and reviews in COPD. Special focus is given to the pathophysiological processes underlying the disease, intervention programs, patient focused education, and self management protocols.

\section{Dovepress}

This journal is indexed on PubMed Central, MedLine and CAS. The manuscript management system is completely online and includes a very quick and fair peer-review system, which is all easy to use. Visit http://www.dovepress.com/testimonials.php to read real quotes from published authors. 